\title{
Earthworms as bio-indicators of chemical pollution in soils with drilling waste
}

\author{
Justyna Kujawska ${ }^{1, *}$, and Małgorzata Pawłowska ${ }^{1}$ \\ ${ }^{1}$ Institute of Renewable Energy Engineering, Lublin University of Technology 40B \\ Nadbystrzycka Street Lublin, Poland
}

\begin{abstract}
The deposited drilling waste may alter the functioning of soil ecosystems by disrupting the soil fauna. The wastes contain toxic compounds such as metals or hydrocarbons, which tend to accumulate in the living. In the research, earthworms were used $\mathrm{u}$ as bio-indicators of soil pollution resulting from the presence of pollution contained in drilling waste. The aim of this study is to evaluation of toxicity of the waste of spent oil and water drilling cuttings to earthworm Eisenia fetida. Oil-based and water-based drilling cuttings were added to soil, used six doses of drilling wastes $(5 \%, 10 \%, 15 \%, 25 \%, 30 \%, 50 \%)$. The results showed that the 45 days LC50 of oil-based drilling cuttings ranged 18\%, LC50 of water-based drilling cuttings ranged $33 \%$. In general, mortality increases with increasing dosage waste.
\end{abstract}

\section{Introduction}

Depletion of crude oil and natural gas from conventional sources has caused an intensive search for alternative hydrocarbons. The global deposits of shale gas are estimated to 200 trillion $\mathrm{m}^{3}$. However, it is only extracted by the United States and China [1]. Other countries, including Poland, have started to exploit the shale gas, but the drilling and hydraulic fracturing technologies raised social concerns. On the one hand, an increase in shale gas extraction could mitigate the emission of greenhouse gases. On the other hand, there is a risk of soil, ground and surface waters, as well as air becoming contaminated.

The produced drilling waste may pollute the environment, but their actual influence is not sufficiently known. Drilling wastes comprise drill cuttings and spent drilling fluid. The chemical composition of drilling wastes is diversified and depends on the type of drilling fluid utilized in the well. Two types of drilling fluids are commonly employed: water- and oil-based (mainly mineral oil). Apart from the basic substances, various additives such as loamy materials, tannins, surfactants,

\footnotetext{
* Corresponding author: j.kujawska@pollub.pl
} 
glycol and metal salts are used. Hence, drilling wastes contain drilling fluid compounds and the compounds which percolate from the soil, such as zinc, lead, and hydrocarbons [2].

Horizontal drilling of Marcellus shale on the depth of $3700 \mathrm{~m}$ produced $500 \mathrm{t}$ of solids, i.e. drill cuttings. These substances were characterized by elevated content of metal and xylenes [1].

Wastes produced in the course of shale gas extraction are stored at the drill site and subsequently transported to a landfill. In Poland, this is the main method of managing this type of wastes. Chemical compounds from the deposited wastes may infiltrate into the environment - mainly soil - and negatively impact the flora and fauna inhabiting it. The influence of drilling wastes on soil is not fully understood.

As far as studies on environmental pollution are concerned, in recent years there has been a growing interest in bioassays. These tests enable a quick assessment of toxicity of soil polluted by chemical compounds, as well as the analysis of pollutant impact on living organisms. The possibility of determining the pollutant dose causing toxicity is an advantage of this method [3].

Assays conducted on earthworms may be used for the evaluation of chemical pollution in soil. Earthworms constitute $60-80 \%$ of animal biomass in soils, having an influence on its quality. Earthworms bioaccumulate pollutants. A coherent relation between earthworms and the concentration of pollutants (mainly metals) in soils make them good biomonitoring organisms [4].

There are few works uses earthworms in monitoring of soil polluted with drilling wastes. There are a number of studies on the toxicity of drilling wastes on aquatic organisms; this is related to the fact that in the United States the drilling wastes were dumped into the ocean for many years. Studies indicate a toxic influence of drilling wastes on living organisms [5-9]. The knowledge about the toxic potential of chemical compounds found in drilling fluids may be used for the assessment of their impact on the environment.

The aim of the work was to evaluate the toxicity of water- and oil-based drilling fluids on the biomass and mortality of earthworms following 7, 14, 30, and 45 days.

\section{Characteristics of soil and waste}

The chernozem soil was collected in the vicinity of Hrubieszów (eastern Poland) from arable soil (up to the depth of $30 \mathrm{~cm}$ ). The water-based drilling wastes were taken from Maćkowice well, where potassium/polymer drilling fluid was used. On the other hand, the oil-based drilling wastes were originated from the well which utilized oil-based drilling fluid. Seven mixtures of soil and drill cuttings were prepared, which differed in respect to the composition. The content of water- and oil-based drill cuttings equaled $5 \%, 10 \%, 15 \%, 25 \%, 30 \%$, and $50 \%$ of weight.

\section{Research methodology}

The assay was carried out in glass containers with the volume of $250 \mathrm{~cm}^{3}$, filled with soil containing an addition of water- and oil-based drilling cuttings.

Each sample contained 10 mature Eisenia fetida earthworms. Chernozem soil constituted the control sample. The water content amounted to $40 \div 60 \%$ (WHC). The assay was carried out over the period of 45 days. The earthworms were fed with 
finely ground manure. Following 7, 14, 30, 45 days since the earthworms were placed in containers, they were weighed and counted. The assay was conducted in triplicate for each mixture. The acute toxicity assay was performed in line with a PM-ISO 11269-1, 1998 standard. This method involves marking the mortality of mature Eisenia fetida earthworms after 7, 14, 30, and 45 days since they were placed in drill cuttings. The mortality coefficient of earthworms after $n$ days was calculated with the following formula:

$$
M_{n}=\frac{\left(A-B_{n}\right)}{A} 100 \%
$$

where:

$A$ - number of live earthworms in the control soil sample

$B_{n}-$ number of live earthworms in polluted soil after n days

$M_{n}$ - mortality coefficient after $\mathrm{n}$ days, $\%$

$n=7,14,30,45$ days.

The lethal dose of LC50 waste was determined according to the linear scale. The mortality points were marked on the y-axis, while the dose of drilling cuttings was marked on the x-axis. The dose of LC50 is determined by the abscissa of the crossing of curve with the straight line corresponding to $50 \%$ mortality [10].

\section{Results}

The addition of drilling waste reduced the viability of Eisenia fetida earthworms when compared with the control sample, that was a chernozem soil (Fig. 1 and 2). However, the mortality of the tested organisms depended on the drill cuttings type and time of the earthworms exposure to the chemicals contained in the waste.

After 7 days of the experiment, the mixtures with the addition of $5,10,15,25$, and $30 \%$ of water-based drilling cuttings do not impact the number of earthworms. Mixtures with 25 and $30 \%$ addition of water-based drilling cuttings resulted in $30 \%$ mortality after 30 days. After 45 days, the mortality in mixtures grows along with the increase in the dose, resulting in the death of all earthworms. In the case of $50 \%$ dose of drilling cuttings, the mortality reached $100 \%$ (Fig. 1).

Mixtures with oil-based drilling cuttings are more toxic for earthworms than the water-based drilling cuttings. Already in the seventh day, the $25 \%$ oil-based drilling cuttings addition resulted in $10 \%$ mortality of earthworms; $30 \%$ addition caused $30 \%$ mortality, whereas $50 \%$ addition was lethal to $100 \%$ of specimens. After 14 days, the $25 \%$ addition of drilling cuttings brought about $25 \%$ mortality; $30 \%$ addition results in $90 \%$ mortality, while $50 \%$ causes all earthworms to die off. After 30 days, half of the specimens in the mixture with $25 \%$ oil-based drilling cuttings addition died, whereas with $30 \%$ dose, the mortality reached $100 \%$. No earthworms survived after 45 days in the mixture with $25 \%$ oil-based addition (Fig. 2). 


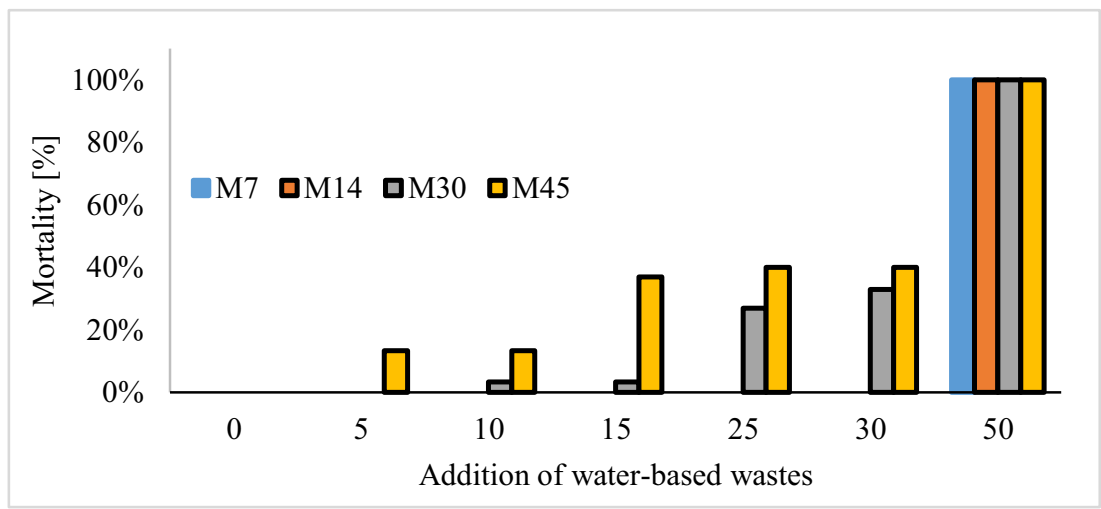

Fig. 1. The mortality coefficient of Eisenia fetida in mixtures containing water-based drilling cuttings after $7,14,30$, and 45 days.

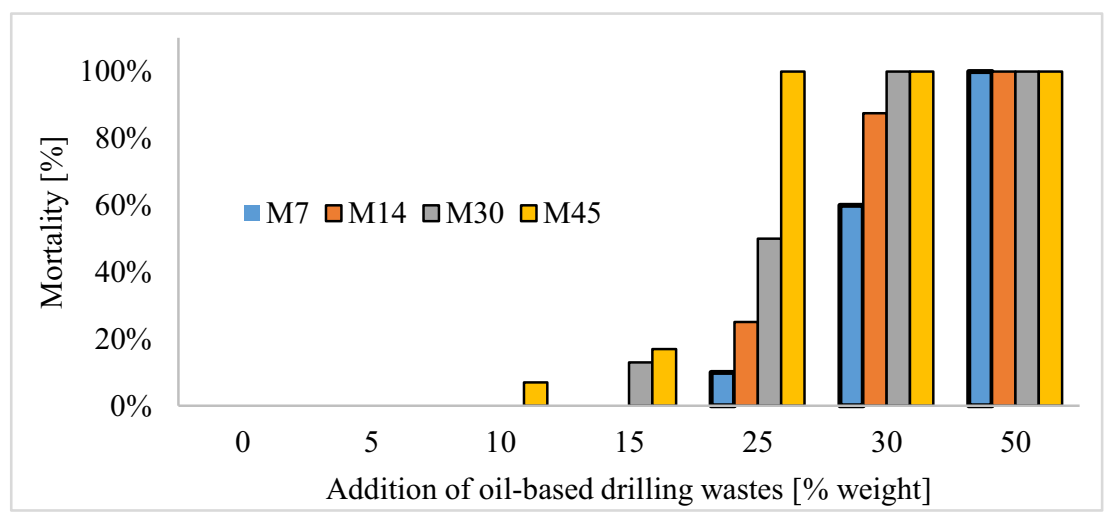

Fig. 2. The mortality coefficient of Eisenia fetida in mixtures containing oil-based drilling cuttings after $7,14,30$, and 45 days.

The LC50 doses calculated on the basis of a linear relation between the waste dose and earthworms mortality after considered time of the experiment duration were presented in table 1 . The dose of water-based drilling cuttings, which resulted in $50 \%$ of earthworms dying off in the considered periods of the time amounted to $33 \%$. In the case of oil-based drilling cuttings, the dose was slightly lower and equalled $25 \%$ for 7,14 , and 30 days of the experiment; after 45 days, the value dropped even further, to $18 \%$. The correlation coefficient for the mixture with waterbased drilling cuttings after 7 and 14 days was moderate, while after 30 and 45 days it was very high. The correlation coefficients for mixtures with oil-based drilling cuttings addition are high. Such values of correlation coefficients indicate strong correlation between the dose and mortality coefficient.

Table 2 presents the impact of drilling cuttings on the biomass of earthworms, following 7, 14, 30, and 45 days. The biomass of earthworms declines greatly with the addition of drilling cuttings. In the case of mixtures with 5,10 , and $15 \%$ addition of water-based drilling cuttings, the biomass of earthworms decreases by the factor of 1.5 after 30 days, whereas after 45 days, it experiences a threefold decrease. With $25 \%, 30 \%$ addition, the biomass is reduced to one-third of the initial value. 
Similar situation occurs in the mixture comprising oil-based drilling cuttings. In mixtures with 5,10 , and $15 \%$ addition, the biomass of earthworms after 30 days reduces by 1.5 , while after 45 days - by 2.5 times in relation to the initial value. In a $25 \%$ oil-based drilling cuttings addition, the biomass is halved after 30 days.

Table 1. The correlation coefficient and the LC50 doses for the mixture with water-based and oil-based drilling wastes.

\begin{tabular}{|c|c|c|c|c|}
\hline \multirow{2}{*}{ Time [days] } & \multicolumn{2}{|c|}{$\begin{array}{c}\text { Mixtures with water-based drilling } \\
\text { wastes }\end{array}$} & $\begin{array}{c}\text { Mixtures with oil-based drilling } \\
\text { wastes }\end{array}$ \\
\cline { 2 - 5 } & Mortality coefficient $\mathrm{R}^{2}$ & LC50 & Mortality coefficient $\mathrm{R}^{2}$ & LC50 \\
\hline 7 & 0.64 & $33 \%$ & 0.85 & $25 \%$ \\
\hline 14 & 0.64 & $33 \%$ & 0.83 & $25 \%$ \\
\hline 30 & 0.91 & $33 \%$ & 0.85 & $25 \%$ \\
\hline 45 & 0.92 & $33 \%$ & 0.76 & $18 \%$ \\
\hline
\end{tabular}

Table 2. Comparison of earthworm biomass in mixtures of soil and drilling cuttings.

\begin{tabular}{|c|c|c|c|c|c|}
\hline \multirow{6}{*}{$\begin{array}{c}\text { Time } \\
\text { Dose of waste }\end{array}$} & Start & After 7 days & $\begin{array}{c}\text { After 14 } \\
\text { days }\end{array}$ & After 30 days & After 45 days \\
\hline \multicolumn{7}{|c|}{ The control sample } \\
\hline 0 & $2.21 \pm 0.30$ & $2.46 \pm 0.35$ & $2.17 \pm 0.23$ & $2.78 \pm 0.37$ & $2.21 \pm 0.25$ \\
\hline \multicolumn{7}{|c|}{ Samples with water-based drilling cuttings addition } \\
\hline$+5 \%$ & $2.27 \pm 0.25$ & $2.93 \pm 0.17$ & $2.21 \pm 0.07$ & $1.41 \pm 0.13$ & $0.68 \pm 0.27$ \\
\hline$+10 \%$ & $2.22 \pm 0.26$ & $2.72 \pm 0.49$ & $2.37 \pm 0.34$ & $1.54 \pm 0.33$ & $0.94 \pm 0.12$ \\
\hline$+15 \%$ & $2.14 \pm 0.27$ & $2.67 \pm 0.59$ & $2.38 \pm 0.40$ & $1.42 \pm 0.27$ & $0.70 \pm 0.16$ \\
\hline$+25 \%$ & $2.11 \pm 0.37$ & $2.46 \pm 0.71$ & $2.30 \pm 0.70$ & $0.67 \pm 0.31$ & $0.65 \pm 0.21$ \\
\hline$+30 \%$ & $2.09 \pm 0.46$ & $2.40 \pm 0.65$ & $2.19 \pm 0.41$ & $0.42 \pm 0.11$ & $0.54 \pm 0.33$ \\
\hline$+50 \%$ & $2.03 \pm 0.35$ & 0 & 0 & 0 & 0 \\
\hline \multicolumn{7}{|c|}{ Samples } & with oil-based drilling cuttings addition & \\
\hline$+5 \%$ & $1.94 \pm 0.16$ & $2.51 \pm 0.34$ & $1.95 \pm 0.21$ & $1.27 \pm 0.1$ & $0.76 \pm 0.03$ \\
\hline$+10 \%$ & $1.96 \pm 0.14$ & $2.52 \pm 0.22$ & $2.21 \pm 0.24$ & $1.12 \pm 0.24$ & $0.61 \pm 0.09$ \\
\hline$+15 \%$ & $2.14 \pm 0.41$ & $2.16 \pm 0.43$ & $1.96 \pm 0.18$ & $1.18 \pm 0.11$ & $0.74 \pm 0.06$ \\
\hline$+25 \%$ & $1.95 \pm 0.36$ & $1.98 \pm 0.51$ & $0.65 \pm 0.09$ & $0.91 \pm 0.71$ & 0 \\
\hline$+30 \%$ & $1.90 \pm 0.54$ & $0.80 \pm 0.34$ & $0.33 \pm 0.21$ & 0 & 0 \\
\hline$+50 \%$ & $1.85 \pm 0.77$ & 0 & 0 & 0 & 0 \\
\hline
\end{tabular}

The obtained results show that the doses of oil- and water-based drilling cuttings which are non-toxic to soil amount to 5 and $10 \%$. Drilling cuttings applied in the higher doses are toxic and when added in higher doses, result in the death of earthworms. This may be related to the presence of such chemical compounds as chromium salts, metals, and surfactants. Oils are compounds which disrupt the nervous system [11]. 
Studies on the impact of drilling waste on living aquatic and soil organisms (earthworms) were conducted. Ogeleka et al., Enuneku and Ayobahan, and Soegianto et al. investigated the influence of drilling fluids on living organisms [5-7]. In all studies, a negative impact of drilling wastes on tested organisms was observed.

The studies were carried out on the solutions decanted from the mixture of drilling mud-to-water in volumetric ratio of 1 to 9. This solution was defined to be $100 \%$ SPP (suspended particulate phase) equal to $1000000 \mathrm{ppm}$ SPP. Any other concentration of SPP refers to a percentage of SPP that was obtained by volumetrically mixing of $100 \%$ SPP with the dilution water. The concentrations of the test solutions used in the studies were $3.125,6.25,12.5,25$ and $50 \%$ (equal to $31250,62500,125000,250000,500000$ ppm SPP).

Enuneku et al. conducted a research on the influence of oil-based drilling fluid and drill cuttings to Aporrectodea longa earthworms. The biomass of earthworms increased in the range of $6.25 \%$ to $12.5 \%$ SPP and decreased when the dose reached $25 \%$ and $50 \%$ of SPP [6]. Soegianto et al. investigated the toxicity of drilling wastes on the tiger prawn larvae (Penaeus monodon). The mortality of the larvae reached $100 \%$ for the dose of $125000 \mathrm{ppm}$ SPP, after 96h [7]. In the research of Ogeleka et al. [5] the dose of oil-based drilling wastes which was $100 \%$ lethal to the brackish water shrimp (Palaemonetes africanus) amounted to $25 \%$ after $72 \mathrm{~h}$ and $50 \%$ SPP after $48 \mathrm{~h}$. The dose which resulted in the death of $50 \%$ of brackish water shrimp after $96 \mathrm{~h}$ equaled 13 , and $18 \%$.

The obtained results and the review of literature indicate a diverse impact of drilling wastes on the biomass of living organisms. Determining the influence of dosage on the pollution of the environment is difficult and mainly dependent on the employed technology and drilling conditions.

In the research carried out by Soegianto et al., the dose of LC50 which resulted in half of the P. monodon larvae dying off amounted to $30000 \mathrm{ppm}$ SPP [7]. Viega et al. investigated the impact of 11 spent drilling fluids on grass shrimp larvae (Palaemonetes intermedius). The doses which killed 50\% of larvae after $96 \mathrm{~h}$ ranged from 142 to $100000 \mathrm{ppm}$ SPP. Other studies conducted by these authors showed that the dose of water-based drilling fluids that caused the death of $50 \%$ of Mysidopsis bahia after 96h, amounted to 27000 ppm SPP [8]. The results obtained by Mexican scientists showed that the dose of water-based drilling fluids which halved the population of Litopenaeus setiferus ranged from 475000 to 700000 ppm SPP.

The dose of wastes which kills $50 \%$ of living organisms varies, similarly to the impact of drilling wastes on their biomass. The lowest dose of drilling wastes which halves the population of organisms amounts to $1.5 \%$. This indicates the necessary of producing drilling fluids characterized by the composition which is safe for the environment.

\section{Conclusions}

Along with the increase in the concentration of drilling cuttings in soil, the mortality grows, while the biomass of earthworms decreases. This means that the compounds in the drilling wastes are toxic to annelids. Mass storage of drilling wastes should be limited due to the negative impact on living organisms, especially earthworms. The studies and the review of literature indicate the diversity of toxic 
dose of drilling wastes, which stems from varied composition of fluids adjusted to the employed drilling technology. Drilling wastes should be treated prior to being stored or managed in other way. Undoubtedly, there is a need for a constant monitoring of the drilling site and landfills of drilling wastes.

\section{References}

1. M.P.J.A. Annevelink, J.A.J. Meesters, A.J. Hendriks, Environmental contamination due to shale gas development, Sci Total Environ 550 (2016)

2. E.O. Abbe, M.S. Grimes, D.G. Fowler, R.A. Boccaccini, J. Material Sci. 60, 1 (2009)

3. A. A Al-Haleem, A. M. Khalid, RJPBCS 7, 6 (2016)

4. T. Hirano, K. Tamae, Sensors 11 (2011)

5. D.F Ogeleka, L.E Tadararo-Aherobo, BEPLS 2 (2013)

6. A. A. Enuneku, S. U. Ayobahan, SU, J. Appl. Sci. Environ. Manage 18, $4(2014)$

7. A. Soegianto, B. Irawan, M. Affand, GJER 2, 1 (2008)

8. L.F. Viega, Z.T. Tostes, M.V. Reynier, G.F.R. Brandao, F.F. Oliveira, Setac 22nd Annual Meeting. Changing Environmental Awareness: Societal Concerns and Scientific Responses (Baltimore, Maryland, USA, 2001)

9. R., F. Nunez, A. Chiappa, M. Vasquez-Botello, C. De la Rosa-Duque, C. Vanegas, Setac 22nd Annual Meeting. Changing Environmental Awareness: Societal Concerns and Scientific Responses (Baltimore, Maryland, USA, 2001)

10. M. Łebkowska, M. Załęska-Radziwiłł, Bożena Słomczyńska, Environmental toxicology (Warsaw University of Technology, Warsaw, 2004) (in polish)

11. W.C. McMordie, Oil base drilling fluids. Symposium on Research on Environmental Fate and Effect of Drilling Fluids and Cuttings (Lake Buena Vista, Florida, USA, 1980) 